\title{
University of South Florida
}

From the SelectedWorks of Carol Ann Davis

May, 2005

Using Customer-Service Software to Manage Serials Online Access

Issues

Carol Ann Borchert 


\section{Using Customer-Service Software to Manage Serials Online Access Issues}

\section{Presented by:}

Carol Ann Borchert

May 20-21, 2005 


\section{University of South Florida}

- One university, geographically dispersed

- Moving towards more centralized Technical Services

- Remote users authenticate via BlackBoard or EZProxy

- Use SFX to link to e-journals 


\section{Statement of Problem}

- Periodic problems in accessing online journals due to inaccurate thresholds, proxy issues, etc.

- Using an email list to manage complaints resulted in things being "lost" in inboxes, no record of problems if similar issue was later reported 


\section{Proposed Solution}

- Use the same software being used by other departments to manage reference questions and technology issues

a Being used by:

- Library Reference Department

- Library Technology Department

- Library Access Services Department

- University Academic Computing Department 


\section{Public or Staff Can Report a Problem}

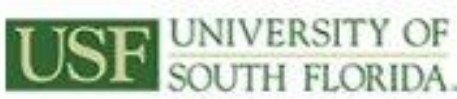

- Search usr - USF Site Map

| Prospective Students | Our Students | Visitors | Faculty \& Starf | Alumni \& Parents | Business \& Community | Campuses | USF > USF Librarieg $>$ Report an SFX Problem

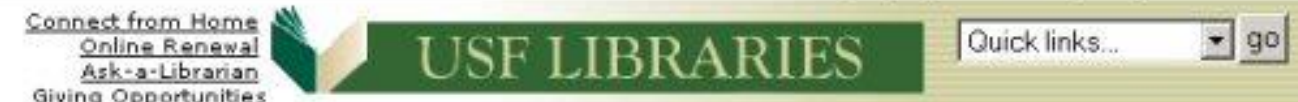
Givine esportunitie:

Report an SFX Problem

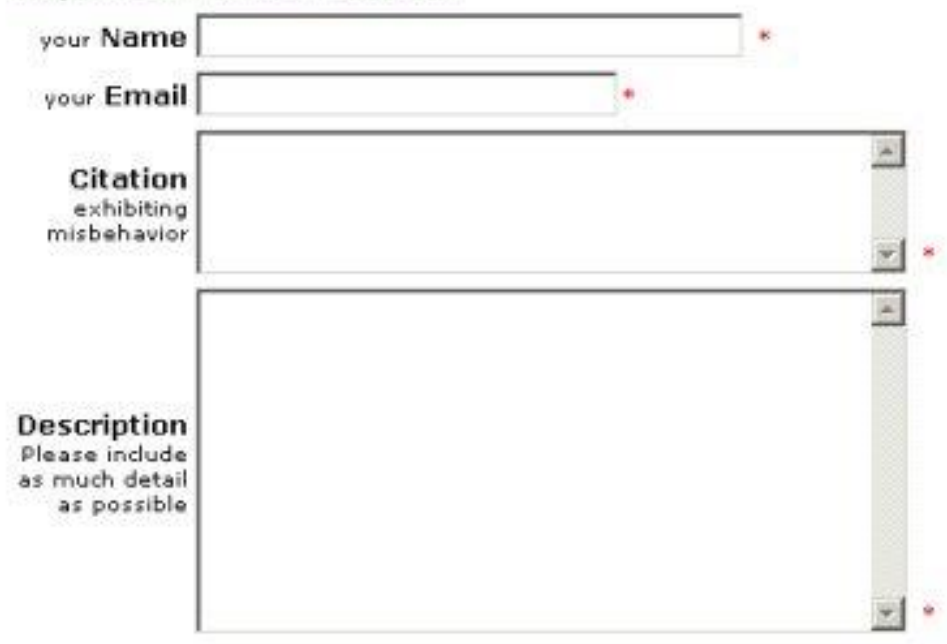

* Required Fields 


\section{Email Copy Received by Staff \\ From: lib-catorikchie acomp usf edu \\ To: Borchert, Carol Arn \\ Cc: \\ Subject: SFX Problem reparted by Karen Keene (Inciderk: 050401-000050)}

The following incident has been assigned to you by: LIB Beverly Caggiano (caggiano@lib usf.edu).

It was previously assigned to: LIB Beverly Caggiano (caggiano@lib.usf edu).

View Incident

Reference $\# 050401-000050$

Summary: SFX Problem reported by Karen Keene

Category: Library

Sub-Category: Cat SFX Issues

Contact Information: kkeene@hsc.usf.edu

Date Created: 04/01/2005 11:15 AM

Last Updated: 04/08/2005 06:18 AM

Status: Unresolved

Priority:

Search Results:

Views:

Chat Transcript:

\section{Discussion Thread}

Note (LIB Beverly Caggiano)

04/08/2005 06:16 AM

I've send Academic Computing the changes. If Lee Ann could test it one more time early next week and let us know if it's still broken, I'd appreciate it.

Note (LIB Carol Ann Borchert)

04/07/2005 04:42 PM

Beverly, could you contact Academic Computing?

Carol Ann

Response (LIB Carol Ann Borchert)

04/07/2005 04:42 PM

Thanks! I'll let Beverly know to contact AC. 


\section{Staff View of Incident List}

\begin{tabular}{|c|c|c|c|}
\hline \multicolumn{4}{|c|}{ め国 } \\
\hline \multicolumn{4}{|l|}{ 口 $\mid \Phi$} \\
\hline \multicolumn{4}{|c|}{ Incident Groups: 4 (containing 161 incidents) } \\
\hline \multicolumn{4}{|l|}{ Top Level } \\
\hline Assigned & Categony $\mathbf{\nabla A}$ & Sub-Categoy $\mathbf{\nabla A}$ & Incidents $\nabla \mathbf{A}$ \\
\hline No value & Library & E-Resource Cataloging & 17 \\
\hline No Value & Library & E-Resource Update & 124 \\
\hline Monica Metz-Wiseman & Librany & Cat SFXIssues & 1 \\
\hline James Michael & Librany & Cat SFXIssues & 4 \\
\hline James Michael & Library & E-Resource Cataloging & 2 \\
\hline James Michael & Librany & E-Resource Update & 11 \\
\hline Carol Ann Borchert & Library & Cat SFXIssues & 2 \\
\hline
\end{tabular}

Logged in as BORCHERT

Page: $1-$ of 1 


\title{
Searching for a Specific Incident
}

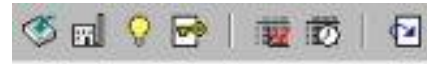

Incident Console

当觔

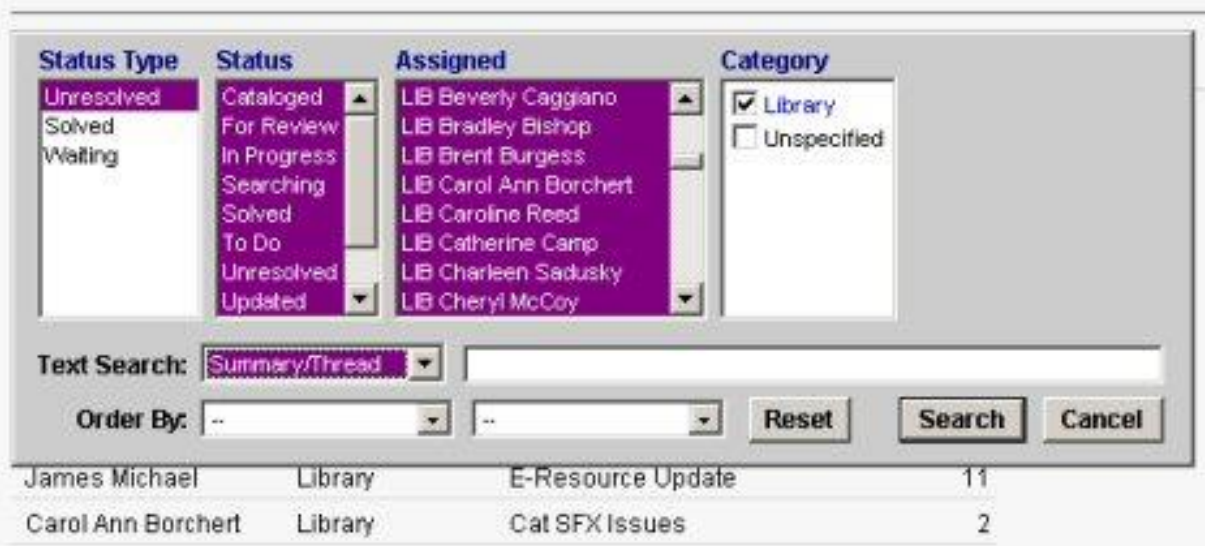




\section{List of Incidents Under My Name}

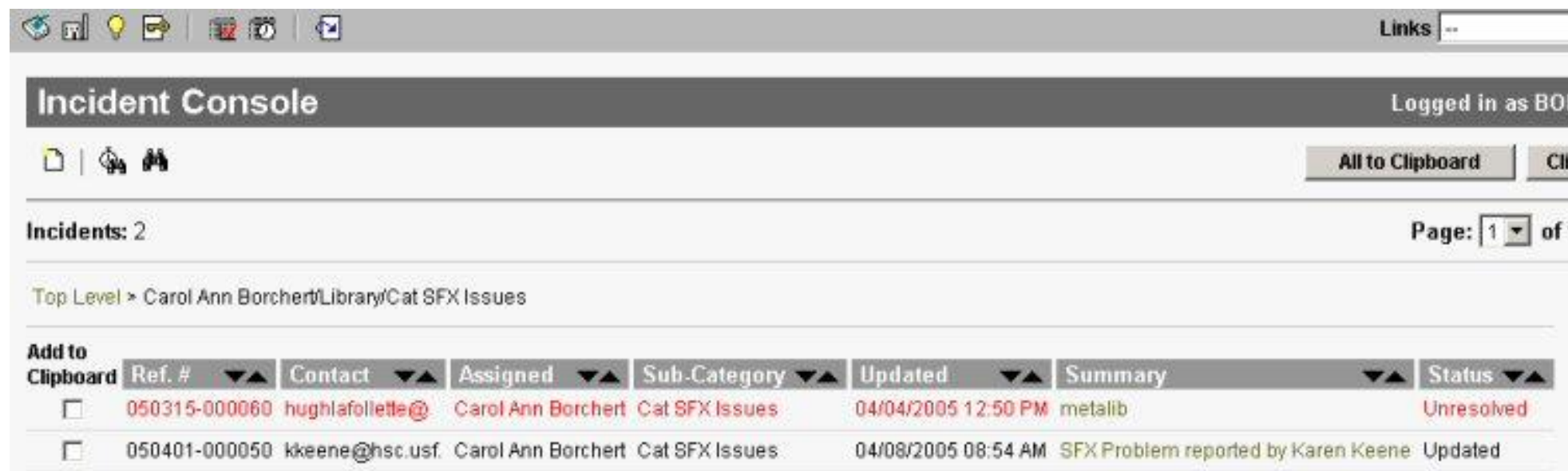




\section{View of an Incident}

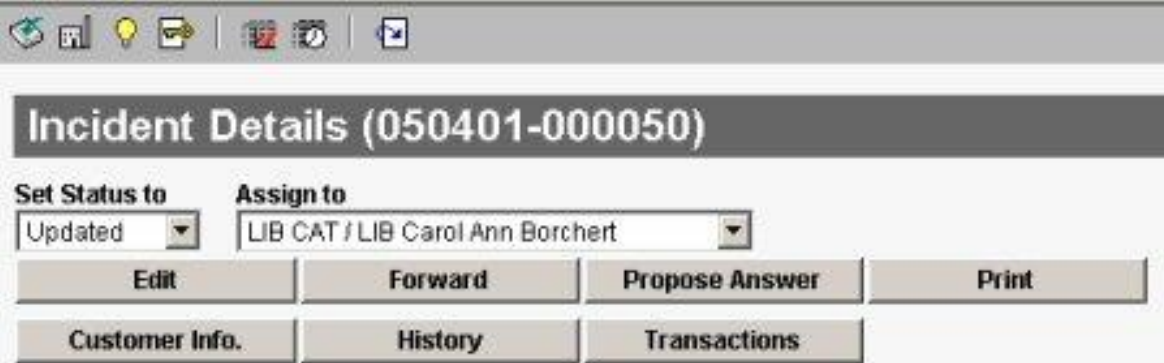

\section{SFX Problem reported by Karen Keene}

\section{Status}

Updated

Assigned to

LQ CAT

Carol Ann Borchert

Category

Lbrary

Cat SFXIssues

Created

04/01/2005 11:15 AM

Initial Response

04/04/2005 12:49 PM

Updated

04/08/2005 08:54 AM

Customer SmartSense

$1=$

Staff SmartSense

in

\section{Discussion Thread}

\section{Note (LiB Carol Ann Borchert)}

Beverly, could you contact Academic Computing?

Carol Ann

Response (LIB Carol Ann Borchert)

Thanks! I'll let Beverly know to contact $A C$.

Carol Ann

Customer

$>$

Hi Carol Ann

Lee Ann tested this from her home for us

It looks like EZProxy is okay now.

She also confirmed that Blackboard Proxy drops.

Her comments are listed below (please notice her comment in the last

Previous Incident

Additional Information

Next Incidemt

Contact E-mail: kkeene@hsc.usf.edu

Priority:

Search Results:

Views:

Chat Transcript: None 


\section{View of Edit Screen for an Incident

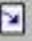

Edit Incident (050401-000050)

\section{\begin{tabular}{l|l|l|} 
Customer Info. & Transactions & History \\
\hline
\end{tabular}}

\section{Discussion Thread}

* Summary: SFXProblem reported by Karen Keene

\section{Previous Entries}

Response (LIB Carol Ann Borchert)

Karen, could you or Lee Ann test this early neit week again via BlackBoard? Beverly has sent the changes to Academic Computing.

04.08/2005 08:54 Ant

Carol Ann

\section{Note (LBB Beverly Caggiano)}

The send Academic Computing the changes. If Lee Ann could test it one more time early next week and let us know if it's still broken, I'd appreciate it

\section{Note (LBB Carol Ann Borchert)}

Beverly, could you contact Academic Computing?

Carol Ann

Response (LIB Carol Ann Borchert)

Thanks! I'Il let Beverh know to contact $A C$.

04:07/2005 04:42 PN

Add: $C$ Customer Entry $\odot$ Response $C$ Note

\begin{tabular}{l}
\hline \\
$\Gamma$ Send Response BCC: \\
F Include Signature In Response \\
Save Cancel
\end{tabular}

Standard Responses

[Circulation]

[Library Document Delivery]

[Library LIRR]

[Reserve]

Open Append

Status: Updated -

Assign to: LIB CAT / LIB Carol Ann Borche

Response Attachments

Spell Check 


\section{Benefits of Using the Software}

- Incidents are no longer mixed in with other email

- We retain a transcript of each incident

- We are able to pull statistical reports each month

- We can record internal notes to each other as well as responses to patrons 


\section{Disadvantages of Using the Software}

- Limitations of the statistics collected

- Takes more time to go to a separate system to resolve problems

- Organization of the data retained is haphazard 


\section{Incidents by Category for the Month \\ $\rightarrow$ Library Category}

Report Time Range: 03/01/2005-03/31/2005

Drill Down to: • Incident Summary

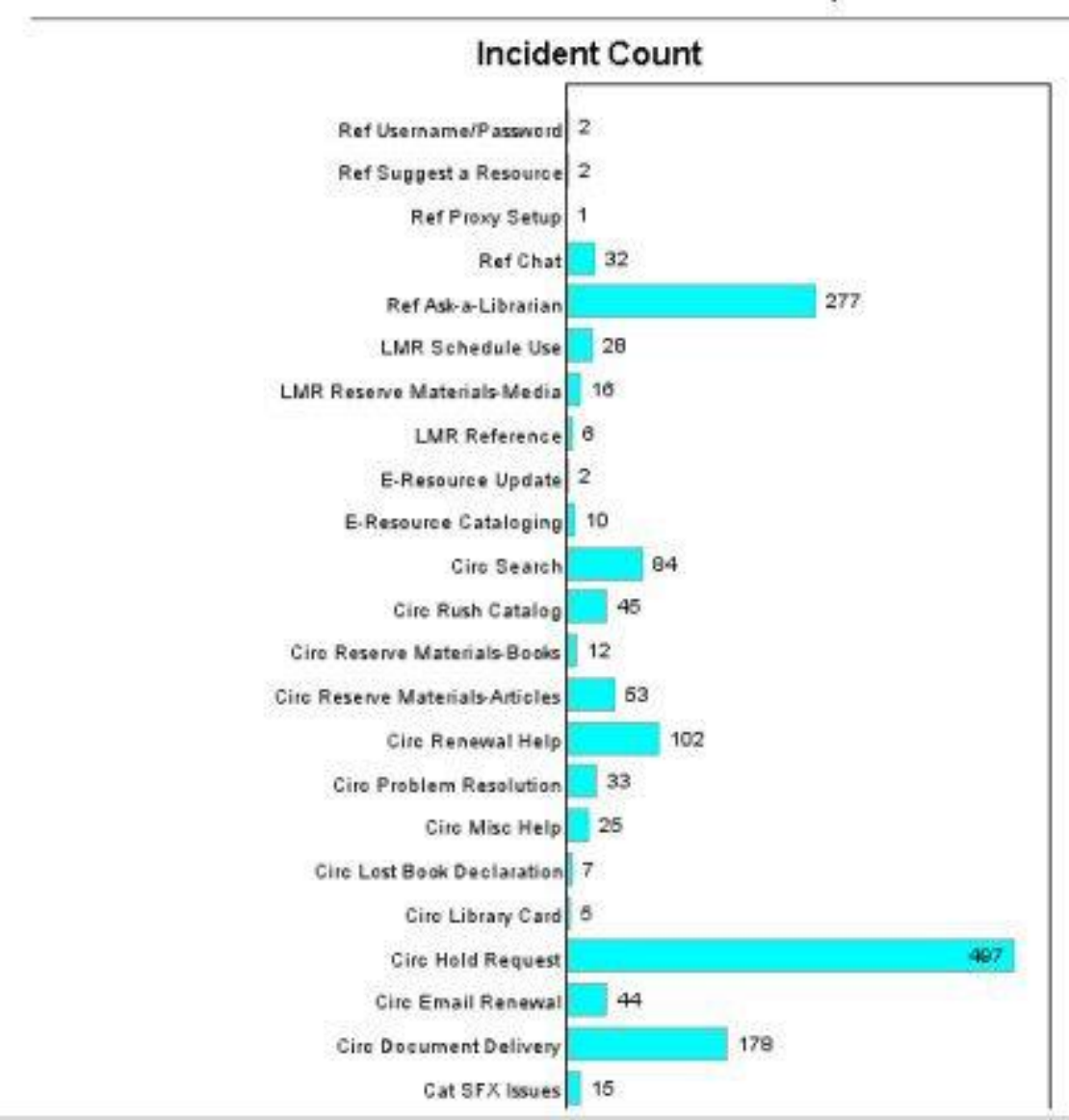




\section{Tabular View of Incidents by}

Category

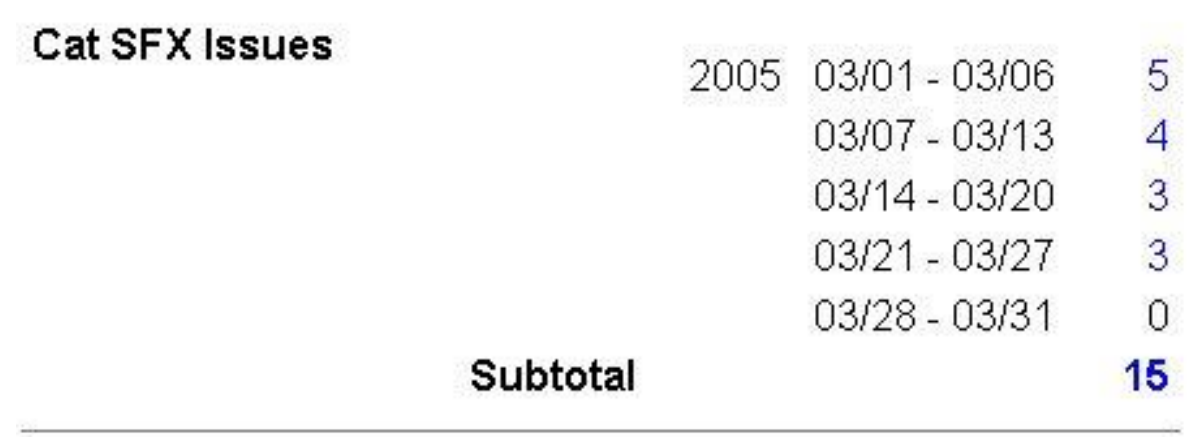

Circ Document Delivery

$\begin{array}{rr}200503 / 01-03 / 06 & 35 \\ 03 / 07-03 / 13 & 11 \\ 03 / 14-03 / 20 & 45 \\ 03 / 21-03 / 27 & 60 \\ 03 / 28-03 / 31 & 27 \\ & 178\end{array}$

Subtotal

178 


\section{Staff Effectiveness by Month}

- Can drill down to an individual's name

\section{Staff Effectiveness}

Selected Groups

Report Time Range: 03/01/2005 - 03/31/2005

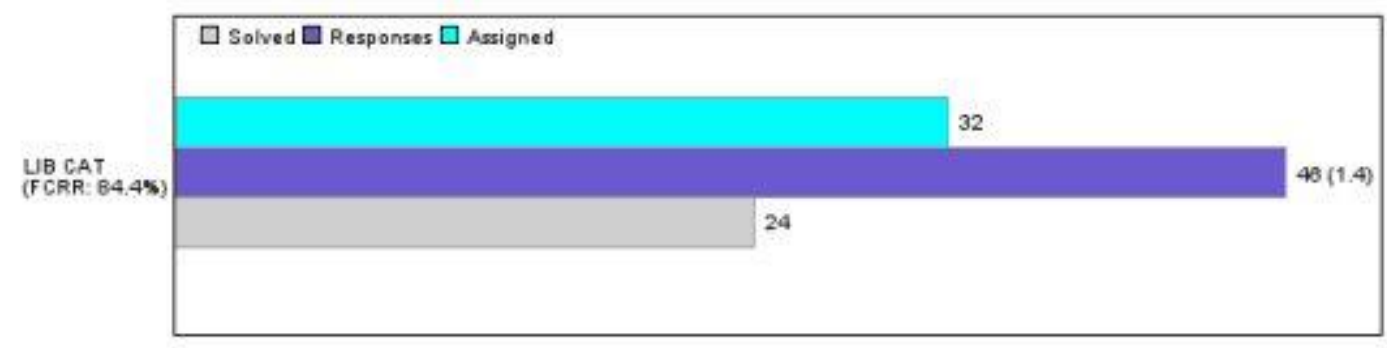




\section{Staff Performance by Month}

\section{Staff Performance}

Selected Staff

Interval Type: Created - Close

Report Time Range: 11/101/2004 - 11/30/2004
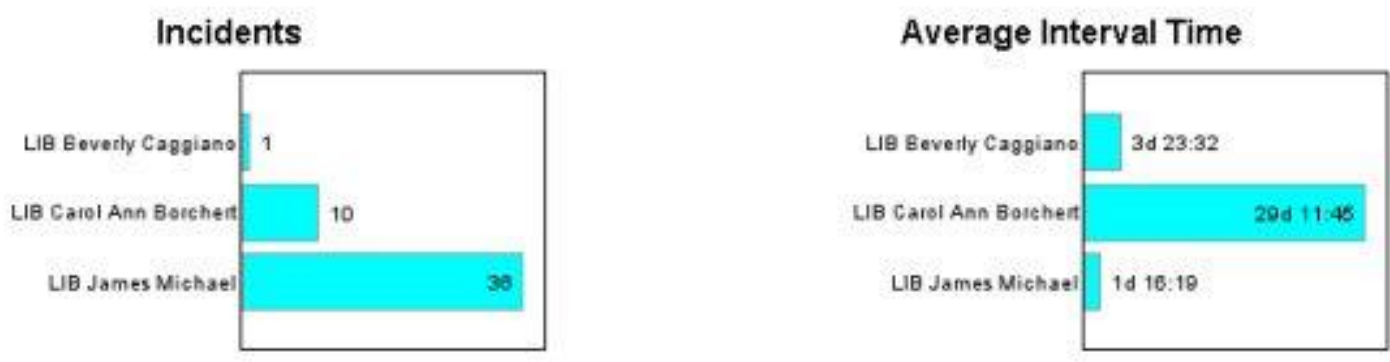


\section{Staff Performance by Incident for the}

\section{Month}

\section{Incident Summary \\ Selection Criteria \\ Interval Type: Created - Close \\ Report Time Range: 11/01/2004 - 11/30/2004 \\ Staff Member: LIB Carol Ann Borchert}

\section{Reference \#}

$040614-000041$

040616-000066

041103-000083

$041108-000131$

041108-000138

$041117-000020$

041118-000071

041118-000146

$041119-000048$

041119-000062

10 incidents found $\sim$ Title

Guifford Publications and ECO subscribers

Current Opinion in Drug Discovery and Development

Re: BioMed Central Off Campus [Incident. 041018-000072]

Re: BioMed Central Off Campus [incident 041018-000072]

Biomed Central

Hypertension Proxy Problem

Philosophy of Science

SIAM Journal on Discrete Mathematics

RE: LEA Online: Media Psychology [Incident. 041011-000053]

October online
-4 Created

$06 / 14 / 2004$

$06 / 16 / 2004$

$11 / 03 / 2004$

$11 / 08 / 2004$

$11 / 08 / 2004$

$11 / 17 / 2004$

$11 / 18 / 2004$

$11 / 18 / 2004$

$11 / 19 / 2004$

$11 / 19 / 2004$

\section{Time}

$142 \mathrm{~d} 09.23$

140d 00:35

od $18: 37$

6d 23.16

3d $21: 46$

od $02: 25$

od 00:00

od 17:15

od 00:13

od 00:00 


\section{Problems Reported via RightNow \\ Software, June 2004-April 2005}

\section{Number of Serials Access Problems Reported}

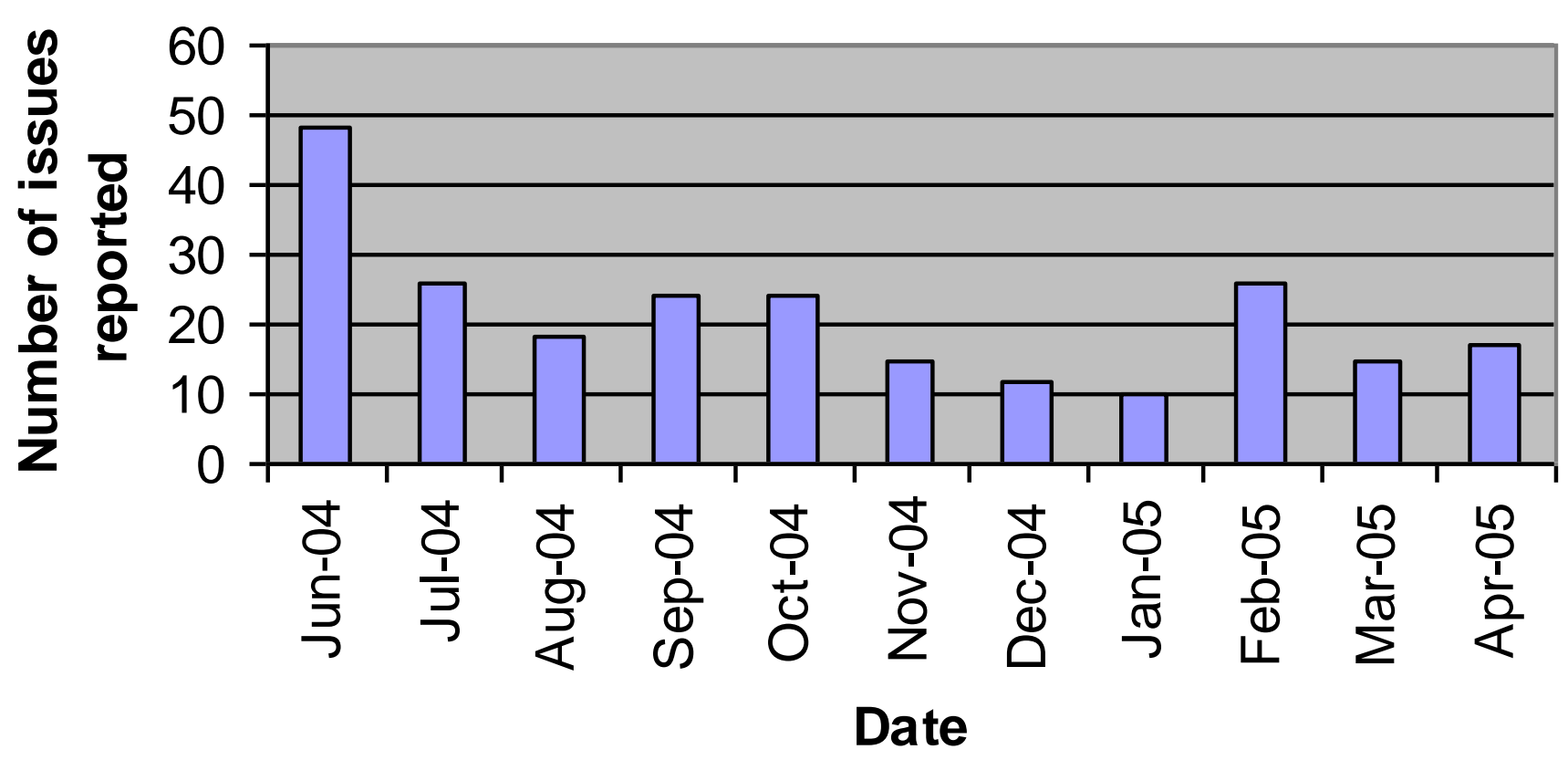




\section{General Considerations When Selecting}

Software

- Are there applications for other departments in your library or organization?

- What do you need the software to do for you?

- What kind of statistics (if any) are available from using that software?

- How is the information archived and organized? How do you search it? 


\section{General Considerations When Selecting}

Software (continued)

- What is the cost of the product?

- What sort of maintenance or upgrades are included in the initial price?

- Be involved in deciding which software to use. 


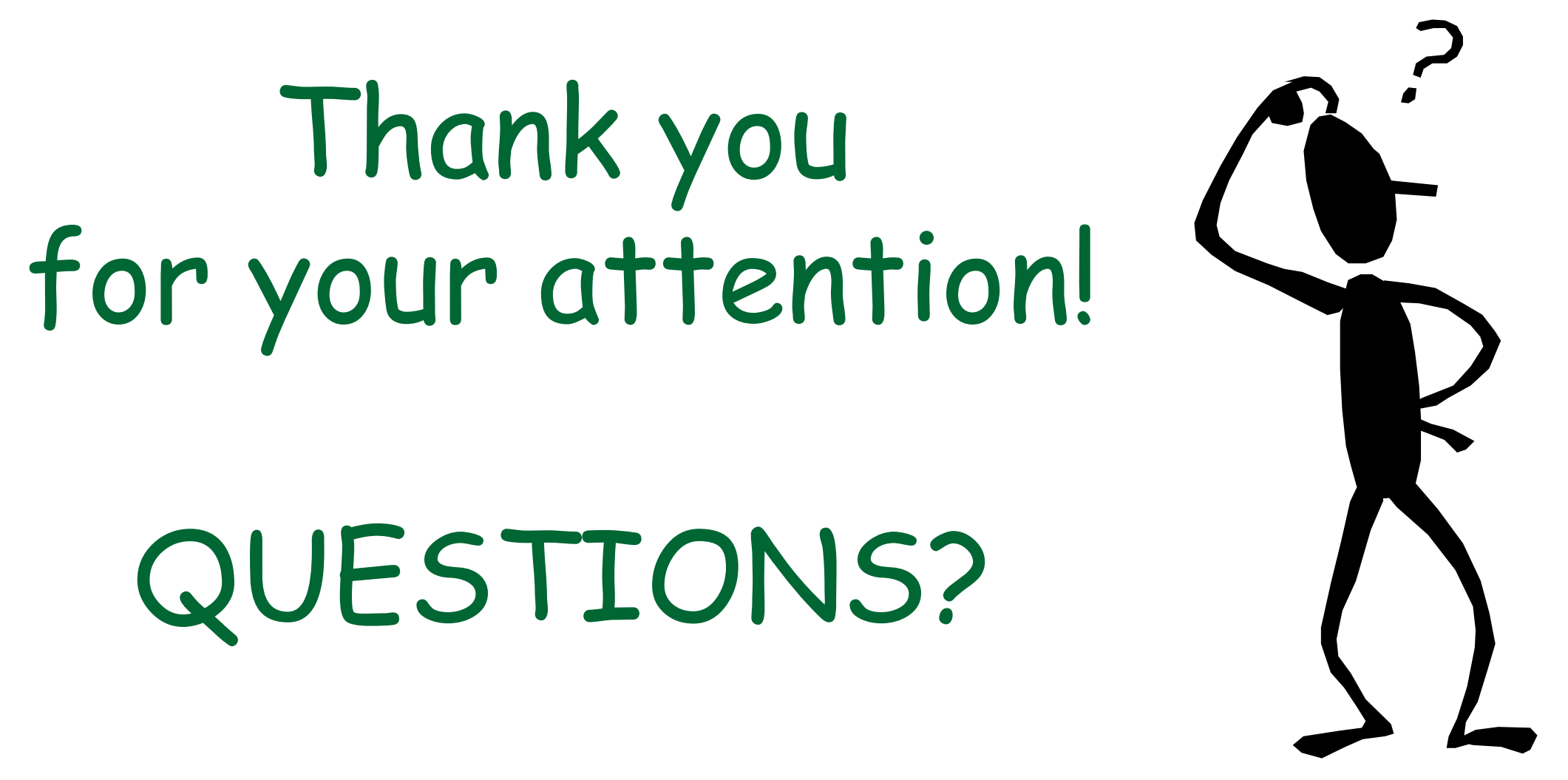

